\title{
Erratum to: A multi-regional soil phosphorus balance for exploring secondary fertilizer potential: the case of Norway
}

\author{
Ola Stedje Hanserud • Eva Brod • \\ Anne Falk Øgaard • Daniel B. Müller • \\ Helge Brattebø
}

Published online: 17 August 2017

(C) Springer Science+Business Media B.V. 2017

\section{Erratum to: Nutr Cycl Agroecosyst (2016) \\ 104:307-320 \\ DOI 10.1007/s10705-015-9721-6}

In the original publication, the units written into Fig. 2b, d, e were incorrectly published, although the units given in the captions were correct. The revised version of the figures are given (Fig. 2).

A1 The online version of the original article can be found under A2 doi:10.1007/s10705-015-9721-6.

A3 O. S. Hanserud ( $\square)$ · E. Brod · A. F. Øgaard

A4 Environment and Climate Division, Norwegian Institute

A5 of Bioeconomy Research (NIBIO), P.O. Box 115,

A6 1431 Aas, Norway

A7 e-mail: ola.hanserud@nibio.no

A8 O. S. Hanserud · D. B. Müller · H. Bratteb $\varnothing$

A9 Industrial Ecology Programme, Norwegian University of

A10 Science and Technology, Sem Sælands vei 7, NTNU,

A11 7491 Trondheim, Norway

\section{A12 E. Brod}

A13 Department of Environmental Sciences, Norwegian

A14 University of Life Sciences, P.O. Box 5003, 1432 Aas, Norway 

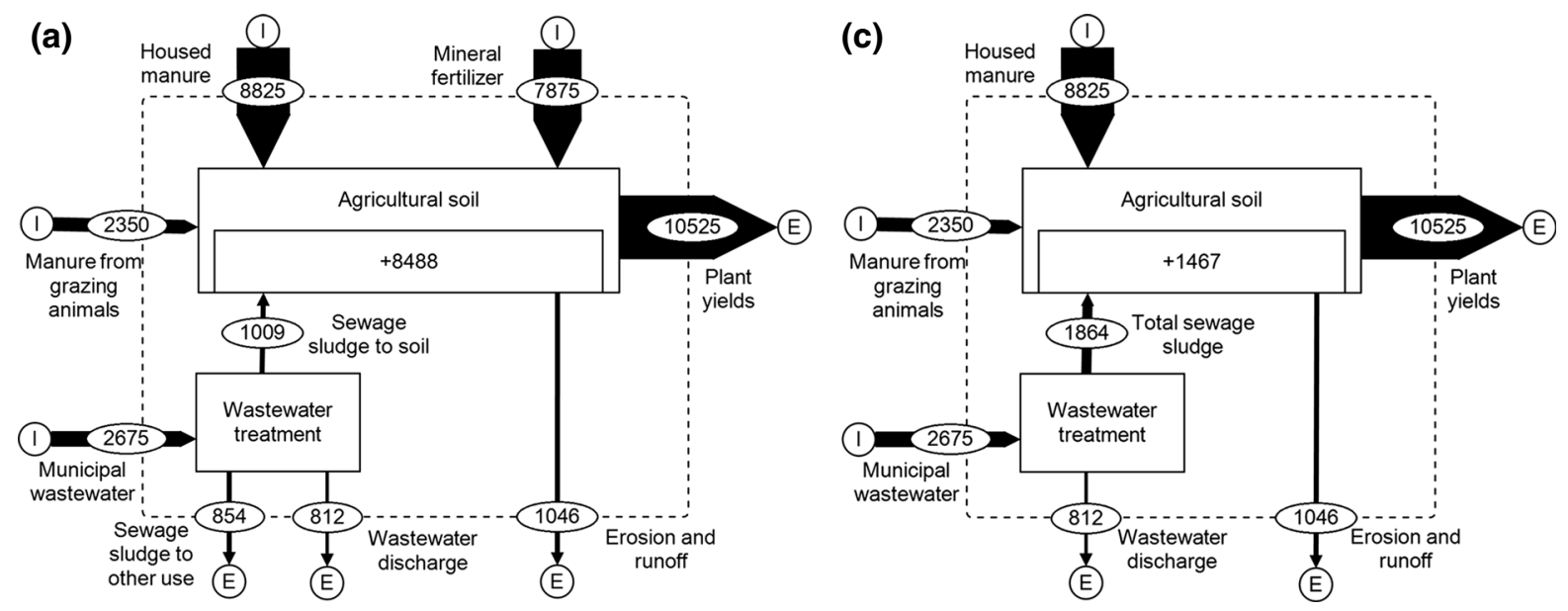
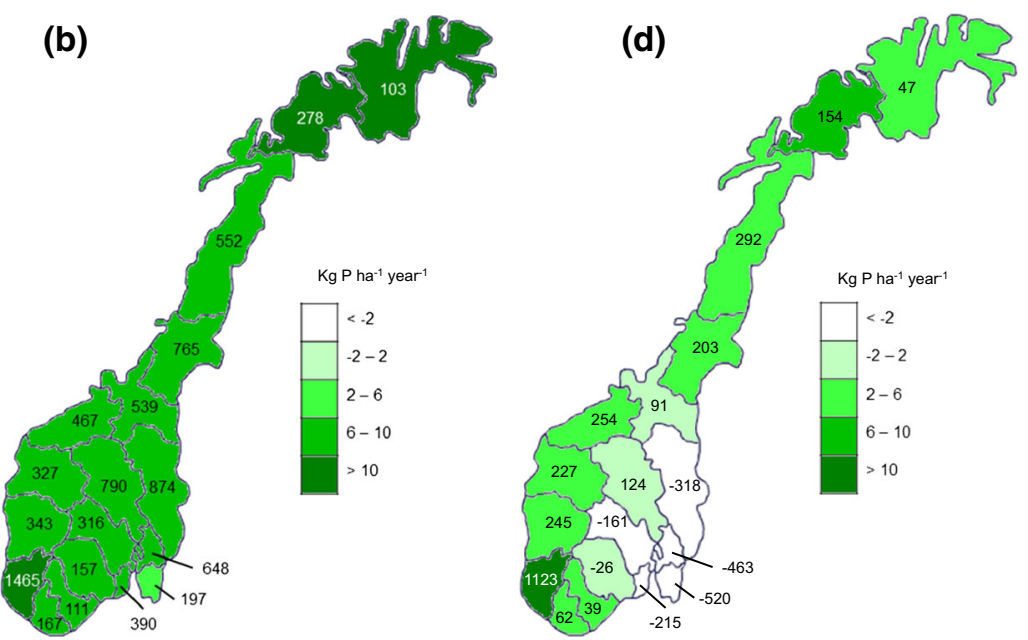

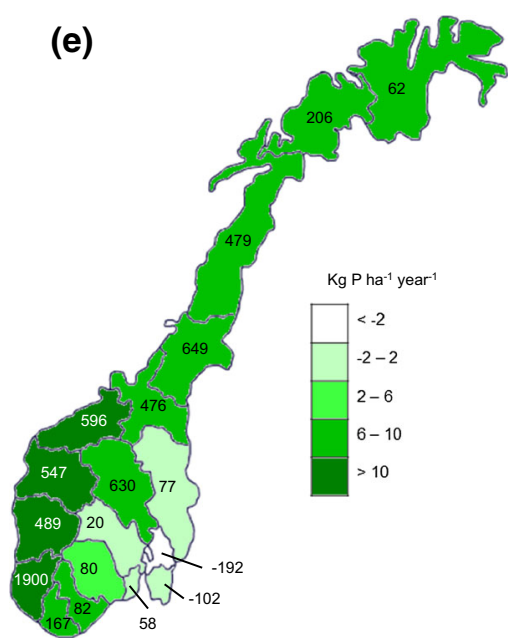

Fig. 2 a FR0: annual $\mathrm{P}$ balance for agricultural soil in Norway (tonnes $\mathrm{P}$ year ${ }^{-1}$ ), 2009-2011. b FR0: annual net stock change (tonnes $\mathrm{P}$ year $\left.{ }^{-1}\right)$ and net stock change per hectare $\left(\mathrm{kg} \mathrm{P}^{-1}\right.$ year ${ }^{-1}$ ), 2009-2011. c FR1 and FR2: annual P balance for agricultural soil in Norway (tonnes $\mathrm{P}_{\text {year }}{ }^{-1}$ ), 2009-2011. d FR1: annual surplus fertilization (tonnes $\mathrm{P}$ year ${ }^{-1}$ ) and surplus fertilization per hectare $\left(\mathrm{kg} \mathrm{P} \mathrm{ha}^{-1}\right.$ year $\left.^{-1}\right), 2009-2011$. e FR2: annual surplus fertilization (tonnes $\mathrm{P}_{\text {year }}{ }^{-1}$ ) and surplus fertilization per hectare $\left(\mathrm{kg} \mathrm{P}^{-1}\right.$ year $\left.^{-1}\right), 2009-2011$ 